\title{
Upper Gastrointestinal Endoscopic Outcomes in Patients with Gastrointestinal Symptoms: Retrospective Analysis at a Tertiary Care Hospital
}

\author{
Iftikhar Haider Naqvi* (D), Abu Talib, Muqadus Tabraze, Omer Mustafa Siddiqui, \\ Maheen Fatima Hussaini, Neha Saleem Paryani, Rida Effendi, Samrah Inam Siddiqui, \\ Syeda Zuhaa Hassan, Maham Munawar, Zaiya Waseem, Ameer Ahmed Khan, \\ Zafir Zohab Hussain Khan, S. Zain Naeem Rizvi, Sofia Fatima Farooqui, Misbah Munaf, \\ Hasan Obaid, Faryal Khan
}

Dow University of Health Sciences, Department of Medicine, Karachi, Pakistan

Email: ^drihnaqvi@mail.com

How to cite this paper: Naqvi, I.H., Talib, A., Tabraze, M., Siddiqui, O.M., Hussaini, M.F., Paryani, N.S., Effendi, R., Siddiqui, S.I., Hassan, S.Z., Munawar, M., Waseem, Z., Khan, A.A., Khan, Z.Z.H., Rizvi, S.Z.N., Farooqui, S.F., Munaf, M., Obaid, H. and Khan, F. (2019) Upper Gastrointestinal Endoscopic Outcomes in Patients with Gastrointestinal Symptoms: Retrospective Analysis at a Tertiary Care Hospital. Open Journal of Gastroenterology, 9, 141-157. https://doi.org/10.4236/ojgas.2019.98017

Received: July 11, 2019

Accepted: August 4, 2019

Published: August 7, 2019

Copyright $\odot 2019$ by author(s) and Scientific Research Publishing Inc. This work is licensed under the Creative Commons Attribution International License (CC BY 4.0).

http://creativecommons.org/licenses/by/4.0/

\section{Open Access}

\begin{abstract}
Background: Endoscopic procedures are frequently performed to rule out any disease process which eventuates with either a positive or negative outcome. Association of patient demographics, clinical features with endoscopic outcomes are of paramount importance for better understanding and practice of endoscopy. Objectives: This study aimed to determine the frequency of positive endoscopic findings in patients with gastrointestinal symptoms compared to those with negative findings. As a secondary objective, the association between relevant demographics, symptoms, laboratory investigations and procedural outcomes of the participants and positive endoscopic findings were also assessed. Methods: A retrospective analysis of all the patients who underwent esophagogastroduodenoscopy from January 2017 to December 2017 was conducted. A total of 1066 endoscopy records were retrieved and using a convenience sampling technique, relevant data were manually entered to the questionnaires. Records with incomplete or inconsistent data were disregarded as per the exclusion criteria, resulting in 1011 patient records ultimately utilized for the study. All data were entered and analyzed using IBM SPSS 23.0. Results: The study comprised a total of 1011 patients where $52.2 \%$ were females and $47.8 \%$ males while the mean age of patients was $42.16 \pm 15.45$. Positive endoscopic findings were observed in $88.1 \%$, where the most common finding was gastritis (49.1\%). Approximately $14.5 \%$ had positive investigation findings for $\mathrm{HBsAg}$ and $23.1 \%$ were seropositive for anti-HCV antibody.
\end{abstract}


P-values statistically significant were for age $(\mathrm{p}=0.044)$, hematemesis $(\mathrm{p}=$ $0.002)$, betel quid addiction $(\mathrm{p}=0.044)$, anti-HCV antibody $(\mathrm{p}=0.043)$, HCV-RNA ( $\mathrm{p}=0.041)$ and " $H$. pylori" antigen $(\mathrm{p}=0.032)$. Conclusion: Both genders were almost equally included where most patients presented between the 3rd and 5th decades of life. A high incidence of gastritis was noted. Positive endoscopic findings were associated with betel quid addiction and with Hepatitis C infection.

\section{Keywords}

Esophagogastroduodenoscopy, Endoscopy, Gastritis, Esophageal Varices

\section{Introduction}

Esophagogastroduodenoscopy or Upper Gastrointestinal (G.I.) Endoscopy gives excellent revelation of the esophagus, stomach and proximal duodenum mucosa. Since its invention in 1958, it has been successfully used to inspect the insides of body cavities [1]. Rudolph Schindler, along with George Wolf, introduced the Wolf-Schindler semiflexible gastroscopy in 1932 [2]. Since its conception, upper G. I. endoscopy has improved dramatically, transforming from a simple visualization tool into one with both vast diagnostic and therapeutic significance.

The United States and other Western countries have shown approximately $25 \%$ annual prevalence of recurrent upper abdominal pain or discomfort which reaches approximately $40 \%$ if heartburn is accounted for it [3]. Other gastrointestinal symptoms such as dysphagia, odynophagia, melena, hematemesis and gastrointestinal bleeding are also considered in healthcare facilities. These gastrointestinal symptoms are related to various diseases which are leading causes of mortality and morbidity worldwide. Upper G.I. endoscopy has a unique value in the diagnosis of various upper G.I. conditions by permitting, apparition, imaging, ultrasonography, and biopsies of suspicious lesions [4]. Esophagitis, gastritis, duodenitis, upper G.I. bleeding, vascular malformations, peptic ulcer disease (PUD) and gastroesophageal reflux disease (GERD) along with various diseases are there for which upper G.I. endoscopy is used to aid the diagnosis [5]. With the ongoing technological advancements in the field of medicine, upper G.I. endoscopy is no longer just a screening or diagnostic procedure but it has a strong therapeutic value such as endoscopic resection for early malignancy arising in Barrett's esophagus [6]. Large balloon pneumatic dilation (PD) and the injection of botulinum toxin (BTI) are being the most common therapeutic intervention used in the treatment of Achalasia [7]. Furthermore, endoscopic ligation is the foremost choice of treatment for bleeding esophageal varices with endoscopic injection sclerotherapy as an alternative [8].

With the growing usage of endoscopy worldwide, this study primarily aimed to represent the procedure-related data of 1011 esophagogastroduodenoscopies performed in the year 2017 at Dr. Ruth K. M. Pfau Civil Hospital Karachi. This 
audit gauged the frequency of positive endoscopic findings in patients with gastrointestinal symptoms compared to those with negative findings. As a secondary objective, the association between relevant demographics, symptoms, laboratory investigations and procedural outcomes of the participants and positive endoscopic findings were also assessed.

To our knowledge, this is the first retrospective study from Pakistan within the last 10 years that evaluated the outcomes of upper gastrointestinal endoscopic procedures in a public, tertiary care hospital setting irrespective of the patients' gender, age or symptoms. This study will serve to inform physicians and gastroenterologists of relevant patient demographics and patterns of endoscopic outcomes to better guide their practice and evaluation of patients.

\section{Methodology}

A retrospective study was conducted in Dr. Ruth K.M. Pfau Civil Hospital, a 1900-bed largest public sector hospital in Karachi, Pakistan, to assess the outcomes of the upper gastrointestinal endoscopic procedures performed in the year 2017. This study included all the patients who presented to Medical Unit 1 for endoscopy and those who were referred from other units. Patient endoscopy records of a total of 1066 consecutively performed upper gastrointestinal endoscopic procedures presenting to the hospital over a period of 1 year, from January 2017 to December 2017, were retrieved from the patients' endoscopy records at the hospital using convenience sampling technique and were entered manually into questionnaires. Only the most recent data for that particular patient in the year of 2017 was entered; other records of prior endoscopies were excluded from the study to prevent the redundancy of data. Some questionnaires had to be excluded due to incomplete or inconsistent data, bringing the final count to 1011.

\subsection{Questionnaire}

A well-structured questionnaire was employed to collect all information. The questionnaire consisted of three parts. The first part included basic demographic details like age, gender and addictions as well as details regarding the patients' family history of G.I. malignancy, acid peptic disease, chronic liver disease and other conditions. The second part dealt with common gastrointestinal symptoms that patients presented with, including abdominal pain, nausea, vomiting, flatulence, heartburn, melena, hematemesis and dysphagia. The last part of the questionnaire was concerned with investigations carried out as well as the endoscopic findings of the patients that were broadly classified into esophageal, gastric or duodenal pathologies. The questionnaire was attached as in Appendix 1. Any patient who presented with one or more of the following was warranted an endoscopy as per the doctors' judgment: upper abdominal pain, heartburn, dysphagia, odynophagia, vomiting, unexplained weight loss, upper gastrointestinal bleeding, anemia, suspected gastrointestinal malignancy and mass in the epigastrium detected on sonography, magnetic resonance imaging or computed to- 
mography scan imaging. To minimize flaws and reduce any sort of bias, the questionnaire was reviewed by two senior doctors and a pilot study was conducted using data from 139 patients. The pretest validity and reliability of the endoscopic questionnaire were determined where the questionnaire was found to be valid (Cronbach alpha 0.71) and reliable.

\subsection{Endoscopy}

All patients included in this study underwent standardized pre-procedure protocols. Patients were kept nil per oral 12 hours prior to the endoscopy and confirmed as being hemodynamically stable with IV lines maintained before and during the procedure. Insertion of the 180 series Olympus video-scopes required $4 \%$ Xylocaine (Lidocaine) nasal spray and Xylocaine gel. The same equipment, protocols and endoscopic expert team were used for all patients, standardizing the level of care.

\subsection{Statistical Analysis}

The data was entered into and analyzed using IBM Statistical Package for the Social Sciences 23.0 (IBM, NY, USA). Chi-square tests were applied to see the relationship of abnormal endoscopic findings with the symptoms and investigations for which the endoscopy was performed.

\section{Results}

\subsection{Demographic Profiles and Comorbid}

The study consisted of 1011 participants with approximately equal participation of females $(n=528,52.2 \%)$ and males $(n=483,47.8 \%)$. The majority of participants belonged to the age groups 20 - 39 years $(\mathrm{n}=399,39.5 \%)$ and $40-59$ years $(\mathrm{n}=394,38.9 \%)$, with the mean age being $42.16 \pm 15.45$. In addition, over $3 / 4$ had not previously undergone endoscopy. In relation to family history of diseases, the overwhelming majority of people had no history of acid peptic disease ( $\mathrm{n}$ $=951,94.1 \%)$, G.I. malignancy $(\mathrm{n}=965,95.5 \%)$, chronic liver disease $(\mathrm{n}=885$, $87.5 \%)$ or other diseases $(n=913,90.3 \%)$. Table 1 displays the demographic details and comorbid of the sample population. Various addictions were found in 281 patients $(27.8 \%)$ where cigarette smoking was the highest $(\mathrm{n}=126,12.5 \%)$ followed by alcohol $(\mathrm{n}=13,1.3 \%)$, naswar $(\mathrm{n}=52,5.1 \%)$, betel quid $(\mathrm{n}=81$, $8.0 \%)$ and betel nut $(\mathrm{n}=9,0.9 \%)$ as shown in Figure 1. Positive endoscopic outcomes in patients having an addiction are also highlighted in Figure 1.

\subsection{Endoscopic Outcomes}

Table 2 illustrates the endoscopic outcomes. Over $7 / 8^{\text {th }}$ exhibited positive endoscopic findings. Among the greater majority of patients $(n=960,95 \%)$, endoscopy was done for all 3 regions; esophagus, stomach and duodenum, where less than $2 / 5^{\text {th }}$ patients were observed to be having normal G.I. mucosa.

1) Esophageal findings 
Table 1. Demographics of the study sample.

\begin{tabular}{|c|c|}
\hline Variable & Frequency \\
\hline \multicolumn{2}{|l|}{ Sex } \\
\hline Male & $483(47.8 \%)$ \\
\hline Female & $528(52.2 \%)$ \\
\hline \multicolumn{2}{|l|}{ Age (Years) } \\
\hline$<20$ & $54(5.3 \%)$ \\
\hline $20-39$ & $399(39.5 \%)$ \\
\hline $40-59$ & $394(38.9 \%)$ \\
\hline $60-79$ & $145(14.3 \%)$ \\
\hline$>79$ & $19(1.9 \%)$ \\
\hline \multicolumn{2}{|c|}{ Previous Endoscopy Done } \\
\hline Yes & $211(20.9 \%)$ \\
\hline No & $800(79.1 \%)$ \\
\hline \multicolumn{2}{|l|}{ Family History } \\
\hline \multicolumn{2}{|l|}{ Acid Peptic Disease } \\
\hline Yes & $60(5.9 \%)$ \\
\hline No & $951(94.1 \%)$ \\
\hline \multicolumn{2}{|l|}{ G.I. Malignancy } \\
\hline Yes & $46(4.5 \%)$ \\
\hline No & $965(95.5 \%)$ \\
\hline \multicolumn{2}{|l|}{ Chronic Liver Disease } \\
\hline Yes & $126(12.5 \%)$ \\
\hline No & $885(87.5 \%)$ \\
\hline \multicolumn{2}{|l|}{ Others } \\
\hline None & $913(90.3 \%)$ \\
\hline Hypertension & $15(1.5 \%)$ \\
\hline Diabetes Mellitus & $31(3.1 \%)$ \\
\hline Tuberculosis & $17(1.7 \%)$ \\
\hline Hepatitis B & $11(1.1 \%)$ \\
\hline Hepatitis C & $24(2.4 \%)$ \\
\hline
\end{tabular}

Table 2. Endoscopic outcomes of the sample population.

\begin{tabular}{lll}
\hline Variable & Yes & No \\
\hline $\begin{array}{l}\text { Positive Endoscopic Findings } \\
\text { Regions where Endoscopy was Performed }\end{array}$ & $891(88.1 \%)$ & $120(11.9 \%)$ \\
1) Esophagus, Stomach and Duodenum & $960(95.0 \%)$ & $51(5.0 \%)$ \\
2) Esophagus and Stomach Only & $25(2.5 \%)$ & $986(97.5 \%)$ \\
3) Esophagus Only & $26(2.5 \%)$ & $985(97.5 \%)$ \\
Normal Upper G.I. Mucosa & $395(39.1 \%)$ & $616(60.9 \%)$ \\
\hline
\end{tabular}




\section{Continued}

\begin{tabular}{|c|c|c|}
\hline \multicolumn{3}{|l|}{ Reflux Esophagitis Grade } \\
\hline None & $884(87.4 \%)$ & $127(12.6 \%)$ \\
\hline Grade 1 & $8(0.8 \%)$ & $1003(99.2 \%)$ \\
\hline Grade 2 & $116(11.5 \%)$ & $895(88.5 \%)$ \\
\hline Grade 3 & $2(0.2 \%)$ & $1009(99.8 \%)$ \\
\hline Grade 4 & $1(0.1 \%)$ & $1010(99.9 \%)$ \\
\hline Gastroesophageal Reflux Disease & $89(8.8 \%)$ & $922(91.2 \%)$ \\
\hline Lax Esophageal Sphincter & $309(30.6 \%)$ & $702(69.4 \%)$ \\
\hline \multicolumn{3}{|l|}{ Esophageal Varices } \\
\hline None & $689(68.2 \%)$ & $322(31.8 \%)$ \\
\hline Grade 1 & $117(11.6 \%)$ & $894(88.4 \%)$ \\
\hline Grade 2 & $183(18.1 \%)$ & $828(81.9 \%)$ \\
\hline Grade 3 & $22(2.2 \%)$ & $989(97.8 \%)$ \\
\hline Esophageal Stricture & $14(1.4 \%)$ & $997(98.6 \%)$ \\
\hline Esophageal Carcinoma & $15(1.5 \%)$ & $996(98.5 \%)$ \\
\hline Gastric Varices & $30(3.0 \%)$ & $981(97 \%)$ \\
\hline Gastritis & $496(49.1 \%)$ & $515(50.9 \%)$ \\
\hline Gastric Erosion & $112(11.1 \%)$ & $899(88.9 \%)$ \\
\hline Gastric Ulcer & $33(3.3 \%)$ & $978(96.7 \%)$ \\
\hline Duodenitis & $63(6.2 \%)$ & $948(93.8 \%)$ \\
\hline Duodenal Ulcer & $22(2.2 \%)$ & $989(97.8 \%)$ \\
\hline Portal Gastropathy & $18(1.8 \%)$ & $993(98.2 \%)$ \\
\hline Banding & $39(3.9 \%)$ & $972(96.1 \%)$ \\
\hline Dilatation & $18(1.8 \%)$ & $993(98.2 \%)$ \\
\hline Other Findings & $58(5.7 \%)$ & $953(94.3 \%)$ \\
\hline
\end{tabular}

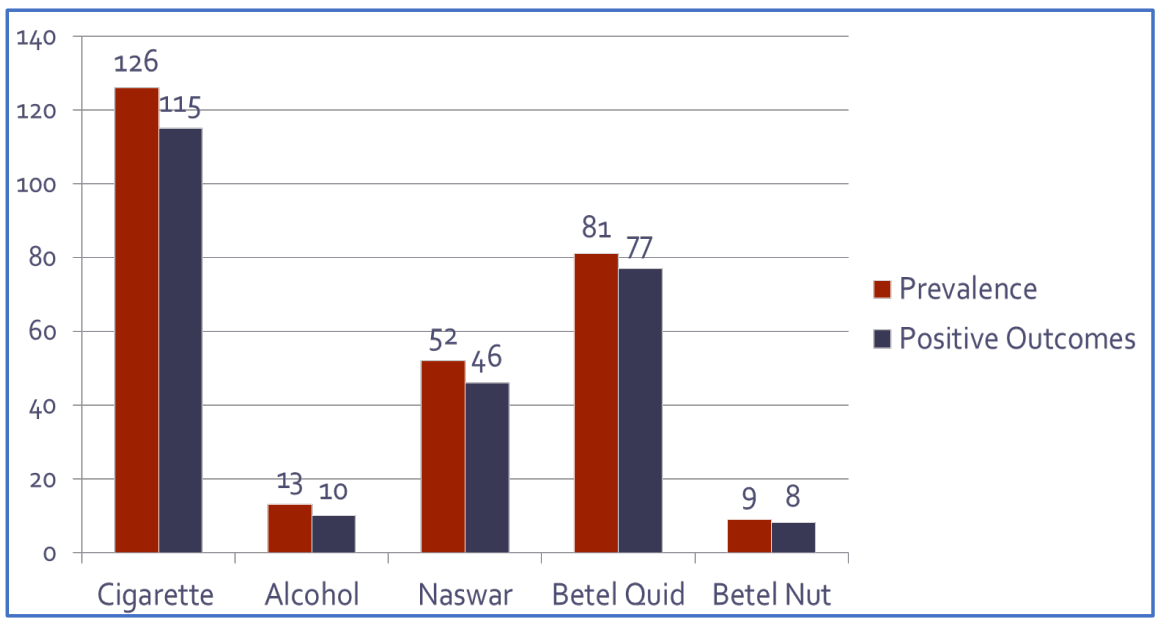

Figure 1. Frequency of various addictions with positive endoscopic findings. 
Majority of patients had reflux esophagitis ( $\mathrm{n}=127,12.6 \%)$, where Grade II reflux was $(n=116,11.5 \%)$ the most common finding, whereas less than $1 / 3^{\text {rd }}$ had a lax esophageal sphincter. In addition, less than $1 / 3^{\text {rd }}$ accounted for having esophageal varices $(n=322,31.8 \%)$ where Grade II esophageal varices was the most common $(n=183,18.1 \%)$ grade. Esophageal strictures $(n=14,1.4 \%)$ and carcinoma $(\mathrm{n}=15,1.5 \%)$ were least reported finding.

\section{2) Gastric findings}

The most common endoscopic outcome was gastritis $(\mathrm{n}=496,49.1 \%)$. Gastric varices $(n=30,3.1 \%)$ had a similar frequency to gastric ulcers $(n=33,3.3 \%)$ with even higher frequency of gastric erosion $(n=112,11.1 \%)$.

\section{3) Duodenal findings}

Duodenitis ( $\mathrm{n}=63,6.2 \%)$ was more frequently present than the duodenal ulcers ( $n=22,2.2 \%$ ) while fairly low frequency were observed for portal hypertensive gastropathy $(n=18,1.8 \%)$ along with other findings $(n=58,5.7 \%)$.

\section{4) Endoscopic interventions}

Banding was done in a few patients $(\mathrm{n}=39,3.9 \%)$ followed by dilatation $(\mathrm{n}=$ $18,1.8 \%)$

\section{5) Association of positive endoscopic outcome with symptoms}

The symptom and investigation-based characteristics of participants stratified with positive endoscopic findings are presented in Table 3. In relation to symptoms indicative of an upper G.I. endoscopy, the most common symptom observed was abdominal pain $(n=626,61.9 \%)$, followed by patients having heartburn $(n=352,34.8 \%)$ and nausea/vomiting $(n=341,33.7 \%)$. The less commonly observed clinical features included abdominal fullness $(n=262.25 .9 \%)$, flatulence $(n=78,7.7 \%)$, hematemesis $(n=179,17.7 \%)$, melena $(n=198,19.6 \%)$, dysphagia $(n=102,10.1 \%)$ and pallor $(n=217,21.5 \%)$. In addition, over $1 / 3^{\text {rd }}$ had normal bowel habits $(\mathrm{n}=466,46.1 \%)$. Statistical significance $(\mathrm{p}<0.05)$ with positive endoscopic findings was only observed for hematemesis $(p=0.002)$. The symptoms of participants stratified with positive endoscopic findings are presented in Table 3.

\section{6) Association of positive endoscopic outcome with investigations}

Regarding investigation findings, the majority of patients had lower than normal hemoglobin values for their respective gender: males $(n=321,66.5 \%$ ) and females $(\mathrm{n}=370,70.1 \%)$. Amongst the most commonly reported abnormal investigations were positive ultrasound findings $(n=273,27.0 \%)$ while approximately $1 / 5^{\text {th }}$ had positive investigation findings for HBV-DNA ( $\mathrm{n}=185,18.3 \%$ ) and anti-HCV antibody $(\mathrm{n}=234,23.1 \%)$. Moreover, almost similar prevalence was observed for abnormal LFTs $(\mathrm{n}=194,19.2 \%)$ and HBV-DNA $(\mathrm{n}=185$, $18.3 \%)$ which was higher than that of positive HBsAg $(n=147,14.5 \%)$ and positive HCV-RNA ( $\mathrm{n}=126,12.5 \%$ ) findings. Furthermore, lower incidences were recorded for abnormal serum proteins $(n=65,6.4 \%)$, presence of ascitic fluid ( $\mathrm{n}$ $=55,5.4 \%), H$. pylori antigen $(\mathrm{n}=61,6.0 \%)$ and other investigations $(\mathrm{n}=35$, $3.5 \%)$. Statistically significant differences were observed for anti-HCV antibody 
Table 3. Characteristics of symptoms and investigations in association with positive endoscopic findings.

\begin{tabular}{|c|c|c|c|}
\hline Variable & Yes & No & p-value \\
\hline \multicolumn{4}{|l|}{ Symptoms } \\
\hline Abdominal Pain & $626(61.9 \%)$ & $385(38.1 \%)$ & 0.254 \\
\hline Nausea/Vomiting & $341(33.7 \%)$ & $670(66.3 \%)$ & 0.914 \\
\hline Abdominal Fullness & $262(25.9 \%)$ & $749(74.1 \%)$ & 0.492 \\
\hline Heartburn & $352(34.8 \%)$ & $65965.2 \%)$ & 0.964 \\
\hline Flatulence & $78(7.7 \%)$ & $933(92.3 \%)$ & 0.566 \\
\hline Hematemesis & $179(17.7 \%)$ & $832(82.3 \%)$ & $0.002^{*}$ \\
\hline Melena & $198(19.6 \%)$ & $813(80.4 \%)$ & 0.178 \\
\hline Dysphagia & $102(10.1 \%)$ & $909(89.9 \%)$ & 0.541 \\
\hline Normal Bowel Habits & $466(46.1 \%)$ & $545(53.9 \%)$ & 0.518 \\
\hline Pallor & $217(21.5 \%)$ & $794(78.5 \%)$ & 0.086 \\
\hline \multicolumn{4}{|l|}{ Investigations } \\
\hline \multicolumn{4}{|l|}{ Abnormal Hemoglobin } \\
\hline Males (<13 gm/dl) & $321(66.5 \%)$ & $162(33.5 \%)$ & 0.371 \\
\hline Females $(<12 \mathrm{gm} / \mathrm{dl})$ & $370(70.1 \%)$ & $158(29.9 \%)$ & 0.254 \\
\hline HBsAg & $147(14.5 \%)$ & $864(85.5 \%)$ & 0.664 \\
\hline HBV-DNA & $185(18.3 \%)$ & $826(81.7 \%)$ & 0.212 \\
\hline Anti-HCV Antibody & $234(23.1 \%)$ & $777(76.9 \%)$ & $0.043^{*}$ \\
\hline HCV-RNA & $126(12.5 \%)$ & $885(87.5 \%)$ & $0.041^{*}$ \\
\hline Positive Ultrasound & $273(27.0 \%)$ & $738(73.0 \%)$ & 0.237 \\
\hline Abnormal LFTs & $194(19.2 \%)$ & $817(80.8 \%)$ & 0.455 \\
\hline Abnormal Serum Proteins & $65(6.4 \%)$ & $946(93.6 \%)$ & 0.910 \\
\hline Ascitic Fluid & $55(5.4 \%)$ & $956(94.6 \%)$ & 0.052 \\
\hline H. pylori Antigen & $61(6.0 \%)$ & $950(94.0 \%)$ & $0.032^{*}$ \\
\hline Others & $35(3.5 \%)$ & $976(96.5 \%)$ & 0.539 \\
\hline
\end{tabular}

$(\mathrm{p}=0.043)$, HCV-RNA $(\mathrm{p}=0.041)$ and H. pylori antigen $(\mathrm{p}=0.032)$ in association with positive endoscopic findings.

\section{7) Association of positive endoscopic outcome with Demographics:}

Table 4 represents the associations of our characteristic demographics with positive endoscopic findings. When inference was made about demographics for positive endoscopicfindings, a slightly greater proportion of males $(n=429$, $88.8 \%$ ) had positive endoscopic outcomes than females $(n=462,87.5 \%)$. Patients with increasing age from 39 to 79 years or even above have shown significant association ( $\mathrm{P}=0.04)$ with positive endoscopic out come. However, majority of patients having age groups of $<20$ years, had positive endoscopic outcomes. Concerning addictions, the overwhelming majority of participants addicted to 
Table 4. Associations of demographics with positive endoscopic findings.

\begin{tabular}{|c|c|c|c|}
\hline Variable & $\begin{array}{l}\text { Positive Endoscopic } \\
\text { Findings }\end{array}$ & $\begin{array}{l}\text { Negative Endoscopy } \\
\text { Findings }\end{array}$ & p-value \\
\hline Sex & & & 0.517 \\
\hline Male & $429(88.8 \%)$ & $54(11.2 \%)$ & \\
\hline Female & $462(87.5 \%)$ & $66(12.5 \%)$ & \\
\hline Age (Years) & & & $0.044^{*}$ \\
\hline$<20$ & $43(79.6 \%)$ & $11(20.4 \%)$ & \\
\hline $20-39$ & $342(85.7 \%)$ & $57(14.3 \%)$ & \\
\hline $40-59$ & $357(90.6 \%)$ & $37(9.4 \%)$ & \\
\hline $60-79$ & $131(90.3 \%)$ & $14(9.7 \%)$ & \\
\hline$>79$ & $18(94.7 \%)$ & $1(5.3 \%)$ & \\
\hline Cigarette Addiction & $115(91.3 \%)$ & $11(8.7 \%)$ & 0.244 \\
\hline Alcohol Addiction & $10(76.9 \%)$ & $3(23.1 \%)$ & 0.209 \\
\hline Naswar Addiction & $46(88.5 \%)$ & $6(11.5 \%)$ & 0.940 \\
\hline Betel Quid Addiction & $77(95.1 \%)$ & $4(4.9 \%)$ & $0.044^{*}$ \\
\hline Betel Nut Addiction & $8(88.9 \%)$ & $1(11.1 \%)$ & 0.944 \\
\hline Previous Endoscopy done & $188(88.9 \%)$ & $23(11.1 \%)$ & 0.625 \\
\hline \multicolumn{4}{|l|}{ Family History } \\
\hline Acid Peptic Disease & $52(86.7 \%)$ & $8(13.3 \%)$ & 0.718 \\
\hline G.I. Malignancy & $41(89.1 \%)$ & $5(10.9 \%)$ & 0.830 \\
\hline Chronic Liver Disease & $118(93.7 \%)$ & $8(6.3 \%)$ & 0.067 \\
\hline Others & & & 0.627 \\
\hline Hypertension & $13(86.7 \%)$ & $2(13.3 \%)$ & \\
\hline Diabetes Mellitus & $27(87.1 \%)$ & $4(12.9 \%)$ & \\
\hline Tuberculosis & $14(82.4 \%)$ & $3(17.6 \%)$ & \\
\hline Hepatitis B & $11(100 \%)$ & $0(0.0 \%)$ & \\
\hline Hepatitis C & $23(95.8 \%)$ & $1(4.2 \%)$ & \\
\hline
\end{tabular}

cigarette smoking $(\mathrm{n}=115,91.3 \%)$, naswar $(\mathrm{n}=46,88.5 \%)$, betel quid $(\mathrm{n}=77$, 95.1\%) and betel nut $(\mathrm{n}=8,88.9 \%)$ exhibited positive endoscopic findings while most of the alcohol addicts $(n=10,76.9 \%)$ have shown positive outcomes as shown Figure 1. Among all addictions only betel squid, has shown statistically significant association with clear endoscopic findings. Positive endoscopic findings were found in $20.8 \%$ patients who had previous endoscopies. Among patients with previous endoscopies, patients having chronic liver disease $(\mathrm{n}=118$, 93.7\%), acid peptic disease $(\mathrm{n}=52,86.7 \%)$, G.I. malignancy $(\mathrm{n}=41,89.1 \%)$, hypertension $(\mathrm{n}=13,86.7 \%)$, diabetes mellitus $(\mathrm{n}=27,87.1 \%)$ and hepatitis $C$ $(\mathrm{n}=23,95.8 \%), \mathrm{B}(\mathrm{n}=11,100 \%)$ have shown positive endoscopic outcome.

\section{Discussion}

This study shows that $11.9 \%$ of patients with gastrointestinal or other symptoms, 
had normal endoscopic findings where the percentage is in accordance with other contemporary studies [9] [10]. Of the many reasons, one explanation can be employing the safe clinical practice of medicine, where investigations or procedures are ordered or carried out as part of the standard care. So, it's rational for someone practicing safe to order a specific procedure without making the patient aware of its purpose in order to avoid subjective issues or to use the same for further confirmation of a physician's initial examination and assessment of the patient to avoid malpractice charges in the future [11]. Another reason for carrying out an endoscopy can be to offer patient satisfaction and comfort, even with vague symptoms or without specific relevant indications as per guidelines for having an endoscopy [12]. In an unaware and biased background owing to minimal medical knowledge and low educational status altogether, denial plays yet another dilemma to the situation. Hence, qualitative evidence of negative findings apart from the clinical inference by the physician is a source of great relief to the patient. Due to these factors, physicians do carry out endoscopic investigations, despite having ruled out significant existing pathology by evaluating symptoms and patient examination.

Furthermore, a study conducted in Multan, Pakistan concluded that $76 \%$ of the participants had functional dyspepsia, a disorder which presents with dyspeptic symptoms without any positive endoscopic findings [13]. Where, functional dyspepsia is yet another entity of substantive gastrointestinal symptoms without documentable endoscopic findings. Consequently, though the expertise of endoscopist is to determine the outcome of a relevant endoscopic finding, however, an unremarkable endoscopy or a miss of endoscopic findings could both be subsequent to lack of experience or error or both at hands of the endoscopist.

The commonest endoscopic finding of this study (49.1\%) was gastritis which is similar to earlier research carried out in Saudi Arabia in 1991 [14]. Pakistan, being a developing country, has colossal variation in the levels of education and socioeconomic stratification of the population. The lower socioeconomic profile entails illiteracy which is associated with improper diet both due to lack of resources as well as knowledge [15]. Therefore, the high incidence of gastritis is attributed to dietary patterns, both in terms of the standard of hygiene and choice of diet. Helicobacter pylori is a key cause of gastritis, which is linked to its mode of transmission via the fecal-oral route explains the high incidence of gastritis. According to Zaidi et al., the Pakistani population has a high occurrence of $H$. pylori infections [16]. The p-value for the presence of $H$. pylori antigen linked with positive endoscopic findings was found to be 0.032 , proving to be statistically quite significant. In addition, the overuse of NSAIDs in Pakistan [17] can also be associated with increased gastritis. NSAIDs function by reducing prostaglandin production via inhibition of the cyclooxygenase pathway; prostaglandins in the gastric mucosa play a vital role in mucosal protection. NSAIDs are also known for increasing gastric acid secretion and reducing gastric mucosal blood supply. The easy commercial availability and rampant use on a self-prescription basis of 
NSAIDs [18] could also embark an important role in the high prevalence of gastritis among our population.

Where seropositivity of HBsAg and anti-HCV antibody being the diagnostic criteria, $14.5 \%(\mathrm{n}=147)$ patients in our study were having Hepatitis B infection compared to $23.1 \%(n=234)$ who were found positive for Hepatitis C infection. Hepatitis $\mathrm{C}$ virus has emerged as the most frequent etiology of chronic liver disease in certain parts of Pakistan [19]. The remarkable endoscopic features are invariably subsequent to the complications of cirrhosis such as portal hypertension, esophageal and gastric varices, peptic ulcer disease leading to gastric ulcers, and portal gastropathy [20]. Subsequently, $31.8 \%$ of the patients in this study were diagnosed with esophageal varices upon endoscopy with the $\mathrm{p}$-value $(\mathrm{P}=$ 0.043) for an association between Hepatitis $C$ infection and positive endoscopic finding which was found to be statistically significant. Furthermore, there is existing literature representing a minor percentage of transmission of such infections via GI endoscopy itself [21] as well as spreads which were secondary to improper methods of sterilization [22]. The aforementioned issue has hoisted an alarming notion regarding the prerequisite to perform GI endoscopy for patients having chronic liver disease, if necessary, with a standardized adequate sterilizing technique protocol employed per se.

Demographically almost equal participation of genders was found, with females comprising $52.2 \%$ and males comprising $47.8 \%$ of the sample population. These figures are in accordance with other studies conducted where the gender segregate was relatively equal [23]. The marginally greater number of women presenting with gastrointestinal symptoms compared to men is a trend noted in other contemporary studies and is further supported by the proposition that the female gender may be an independent risk factor for dyspepsia [24], a clinical spectrum of gastrointestinal symptoms including, but not limited to, abdominal pain associated with nausea, vomiting and heartburn. An existing elucidation proposes that increased prevalence of stress and anxiety disorders in females [25] as additional risk factors themselves can trigger bouts of dyspepsia, as well as other gastrointestinal symptoms. However, this study also establishes $88.8 \%$ of our male participants to be having positive endoscopic findings as compared to $87.5 \%$ of females which in turn suggests females to more likely suffer from functional dyspepsia than males, as shown by existing literature [26].

The age pattern shows that the presentation of endoscopic features is most likely to arise in or around the 3rd to 5th decades of life, a statistic in line with other studies [23]. The analysis identified positive endoscopic findings in $90.1 \%$ of the participants aged 40 years old and above as compared to $84 \%$ in the ones younger than 40 years. Not only have certain studies established associations between age and positive endoscopic findings [27], the American Society for Gastrointestinal Endoscopy guidelines particularly advocate endoscopy in dyspeptic patients above the age of 45 years a recommendation supported by our significant $\mathrm{p}$-value $(0.044)$ associating age with any positive endoscopic finding. 
Among the numerous addictions noted within our sample population, a positive association was found between the use of betel quid and positive endoscopic findings. The use of betel quid (which is a mixture of betel leaf, tobacco, areca nut and slaked lime) has previously been linked to an increased risk of developing peptic ulceration along with oral and esophageal carcinoma, as outlined in a study conducted among Pakistani population [28]. This is specifically a result of nitrosamine based compounds derived from the 4 constituents of betel (namely guvacoline, arecaidine, arecoline and guvacine), where all have potential carcinogenic properties [29]. These components present in betel induce the release of pro-inflammatory cytokines and chemicals while further potentiating the damage caused. This viciously leads to systemic chronic inflammation, widespread damage and the development of multi-systemic diseases [30]. Interestingly though while an awe-inspiring majority of our participants with addiction to smoking had discernable positive endoscopic findings (91.3\%), despite having early evidence of positive correlation between smoking and positive endoscopic findings [28], this study could not demonstrate a statistically significant association between the two which is in contrast to earlier study reported on the same subject.

This study has one notable limitation. The entire data used in this study was obtained retrospectively from patient records. As such, any existing discrepancies in the database would have adversely affected our outcomes and findings.

The patients presenting for esophagogastroduodenoscopy are approximately equal in terms of participation of both genders, however, there is a noticeable age distribution with most patients presenting between the $3^{\text {rd }}$ and $5^{\text {th }}$ decades of life. The majority of patients presenting for Esophagogastroduodenoscopy had positive endoscopic outcomes. The vast majority of patients presenting with addictions went on to have positive endoscopic findings; particularly the use of betel quid which has a statistical significance. Gastritis and HCV had significant associations established with positive endoscopic findings.

\section{Statement of Ethics}

Exemption has been sought from Institution review board for this study.

\section{Funding Sources}

The authors declare that they have not received any financial support for this article.

\section{Conflicts of Interest}

The authors have no conflicts of interest to declare.

\section{References}

[1] Early, D.S., Ben-Menachem, T., Decker, G.A., Evans, J.A., Fanelli, R.D., Fisher, D.A., et al. (2012) Appropriate Use of GI Endoscopy. Gastrointestinal Endoscopy, 75, 1127-1131. https://doi.org/10.1016/j.gie.2012.01.011 
[2] Ro, T.H., Mathew, M.A. and Misra, S. (2015) Value of Screening Endoscopy in Evaluation of Esophageal, Gastric and Colon Cancers. World Journal of Gastroenterology, 21, 9693-9706. https://doi.org/10.3748/wjg.v21.i33.9693

[3] Talley, N.J., Vakil, N.B. and Moayyedi, P. (2005) American Gastroenterological Association Technical Review on the Evaluation of Dyspepsia. Gastroenterology, 129, 1756-1780. https://doi.org/10.1053/j.gastro.2005.09.020

[4] Tytgat, G. (2002) Role of Endoscopy and Biopsy in the Work up of Dyspepsia. Gut, 50, iv13-iv16. https://doi.org/10.1136/gut.50.suppl_4.iv13

[5] Dronfield, M.W., McIllmurray, M.B., Ferguson, R., Atkinson, M. and Langman, M.J. (1977) A Prospective, Randomised Study of Endoscopy and Radiology in Acute Upper-Gastrointestinal-Tract Bleeding. The Lancet, 309, 1167-1169.

https://doi.org/10.1016/S0140-6736(77)92713-1

[6] Pouw, R.E., Seewald, S., Gondrie, J.J., Deprez, P.H., Piessevaux, H., Pohl, H., et al. (2010) Stepwise Radical Endoscopic Resection for Eradication of Barrett's Oesophagus with Early Neoplasia in a Cohort of 169 Patients. Gut, 59, 1169-1177. https://doi.org/10.1136/gut.2010.210229

[7] Stavropoulos, S.N., Friedel, D., Modayil, R., Iqbal, S. and Grendell, J.H. (2013) Endoscopic Approaches to Treatment of Achalasia. Therapeutic Advances in Gastroenterology, 6, 115-135. https://doi.org/10.1177/1756283X12468039

[8] Dai, C., Liu, W.-X., Jiang, M. and Sun, M.-J. (2015) Endoscopic Variceal Ligation Compared with Endoscopic Injection Sclerotherapy for Treatment of Esophageal Variceal Hemorrhage: A Meta-Analysis. World Journal of Gastroenterology, 21, 2534-2541. https://doi.org/10.3748/wjg.v21.i8.2534

[9] Agbakwuru, E.A., Fatusi, A.O., Ndububa, D.A., Alatise, O.I., Arigbabu, O.A. and Akinola, D.O. (2006) Pattern and Validity of Clinical Diagnosis of Upper Gastrointestinal Diseases in South-West Nigeria. African Health Sciences, 6, 98-103.

[10] Ayana, S.M., Swai, B., Maro, V. and Kibiki, G.S. (2014) Upper Gastrointestinal Endoscopic Findings and Prevalence of Helicobacter pylori Infection among Adult Patients with Dyspepsia in Northern Tanzania. Tanzania Journal of Health Research, 16, 16-22. https://doi.org/10.4314/thrb.v16i1.3

[11] Baqir, S.M. (2014) Pakistan Cannot Afford Defensive Medicine. Journal of the College of Physicians and Surgeons-Pakistan, 24, 703-704.

[12] Rabeneck, L., Wristers, K., Souchek, J. and Ambriz, E. (2003) Impact of Upper Endoscopy on Satisfaction in Patients with Previously Uninvestigated Dyspepsia. Gastrointestinal Endoscopy, 57, 295-299. https://doi.org/10.1067/mge.2003.122

[13] Anwar, S.O., Ambreen, S. and Ashraf, H.M. (2010) Frequency of Peptic Ulcer Disease in Patients of Dyspepsia An Analysis of Upper Gastrointestinal Endoscopy. PAFMJ-Pakistan Armed Forces Medical Journal, 60, 26-29.

[14] Al-Quorain, A., Satti, M.B., Al-Hamdan, A., al-Ghassab, G., al-Freihi, H. and al-Gindan, Y. (1991) Pattern of Upper Gastrointestinal Disease in the Eastern Province of Saudi Arabia. Endoscopic evaluation of 2,982 patients. Tropical and Geographical Medicine, 43, 203-208.

[15] Safdar, N.F., Bertone-Johnson, E., Cordeiro, L., Jafar, T.H. and Cohen, N.L. (2014) Dietary Patterns of Pakistani Adults and Their Associations with Sociodemographic, Anthropometric and Life-Style Factors. Journal of Nutritional Science, 2, e42. https://doi.org/10.1017/jns.2013.37

[16] Zaidi, S.F. (2016) Helicobacter pylori Associated Asian Enigma: Does Diet Deserve Distinction? World Journal of Gastrointestinal Oncology, 8, 341-350. 
https://doi.org/10.4251/wjgo.v8.i4.341

[17] Gul, S. and Ayub, M. (2014) Prevalence of Prescribing Pattern of More than One NSAID in Pakistan. Journal of Scientific and Innovative Research, 3, 148-154.

[18] Thapa, S., Shankar, P.R., Palaian, S. and Aljadhey, H. (2016) Promoting Rational Self-Medication of Nonsteroidal Anti-Inflammatory Drugs in Nepal. Archives of Pharmacy Practice, 7, 61-66. https://doi.org/10.4103/2045-080X.181035

[19] Farooqi, J.I., Farooqi, R.J. and Khan, N. (2011) Frequency of Hepatitis B and C in Selected Groups of Population in NWFP, Pakistan. Journal of Postgraduate Medical Institute (Peshawar-Pakistan), 21, 165-168.

[20] Krystallis, C., Masterton, G.S., Hayes, P.C. and Plevris, J.N. (2012) Update of Endoscopy in Liver Disease: More than Just Treating Varices. World Journal of Gastroenterology, 18, 401-411. https://doi.org/10.3748/wjg.v18.i5.401

[21] Zill-e-Humayun, M., Ahmed, I. and Hussain, T. (2007) Risk of Transmission of Hepatitis B and C Viruses in Upper Gastrointestinal Endoscopy-A Hospital Based Study. Pakistan Armed Forces Medical Journal, 57, 113-117.

[22] Ishino, Y., Ido, K. and Sugano, K. (2005) Contamination with Hepatitis B Virus DNA in Gastrointestinal Endoscope Channels: Risk of Infection on Reuse after On-Site Cleaning. Endoscopy, 37, 548-551. https://doi.org/10.1055/s-2005-861316

[23] Mehmood, K., Saeedi, M.I., Muhammad, R. and Din, Z. (2006) Upper Gastrointestinal Endoscopic Findings in Patients with Dyspepsia. Journal of Postgraduate Medical Institute (Peshawar-Pakistan), 20, 70-73.

[24] Mahadeva, S. and Goh, K.-L. (2006) Epidemiology of Functional Dyspepsia: A Global Perspective. World Journal of Gastroenterology, 12, 2661-2666. https://doi.org/10.3748/wjg.v12.i17.2661

[25] McLean, C.P., Asnaani, A., Litz, B.T. and Hofmann, S.G. (2011) Gender Differences in Anxiety Disorders: Prevalence, Course of Illness, Comorbidity and Burden of Illness. Journal of Psychiatric Research, 45, 1027-1035. https://doi.org/10.1016/j.jpsychires.2011.03.006

[26] Shaib, Y. and El-Serag, H.B. (2004) The Prevalence and Risk Factors of Functional Dyspepsia in a Multiethnic Population in the United States. The American Journal of Gastroenterology, 99, 2210-2216.

[27] Adang, R.P., Vismans, J.F., Talmon, J.L., Hasman, A., Ambergen, A.W. and Stockbrügger, R.W. (1995) Appropriateness of Indications for Diagnostic Upper Gastrointestinal Endoscopy: Association with Relevant Endoscopic Disease. Gastrointestinal Endoscopy, 42, 390-397. https://doi.org/10.1016/S0016-5107(95)70037-4

[28] Ahmed, W., Qureshi, H., Alam, S.E. and Zuberi, S.J. (1993) Association of Upper Gastrointestinal Lesions with Addictions. Journal of the Pakistan Medical Association, 43, 176-177.

[29] IARC Working Group on the Evaluation of Carcinogenic Risks to Humans, World Health Organization, International Agency for Research on Cancer. Betel-Quid and Areca-Nut Chewing and Some Areca-Nut-Derived Nitrosamines. IARC; 2004.

[30] Chang, L.-Y., Wan, H.-C., Lai, Y.-L., Kuo, Y.-F., Liu, T.-Y., Chen, Y.-T. and Hung, S.-L. (2009) Areca Nut Extracts Increased Expression of Inflammatory Cytokines, Tumor Necrosis Factor- $\alpha$, Interleukin-1 $\beta$, Interleukin-6 and Interleukin-8, in Peripheral Blood Mononuclear Cells. Journal of Periodontal Research, 44, 175-183. https://doi.org/10.1111/j.1600-0765.2008.01104.x 


\section{Appendix 1}

Form number

OUTCOME OF UPPER G.I. ENDOSCOPY DURING 2017: A RETROSPECTIVE STUDY

Consent: Prior consent have already been taken on patients file

\section{Section I: Biodata}

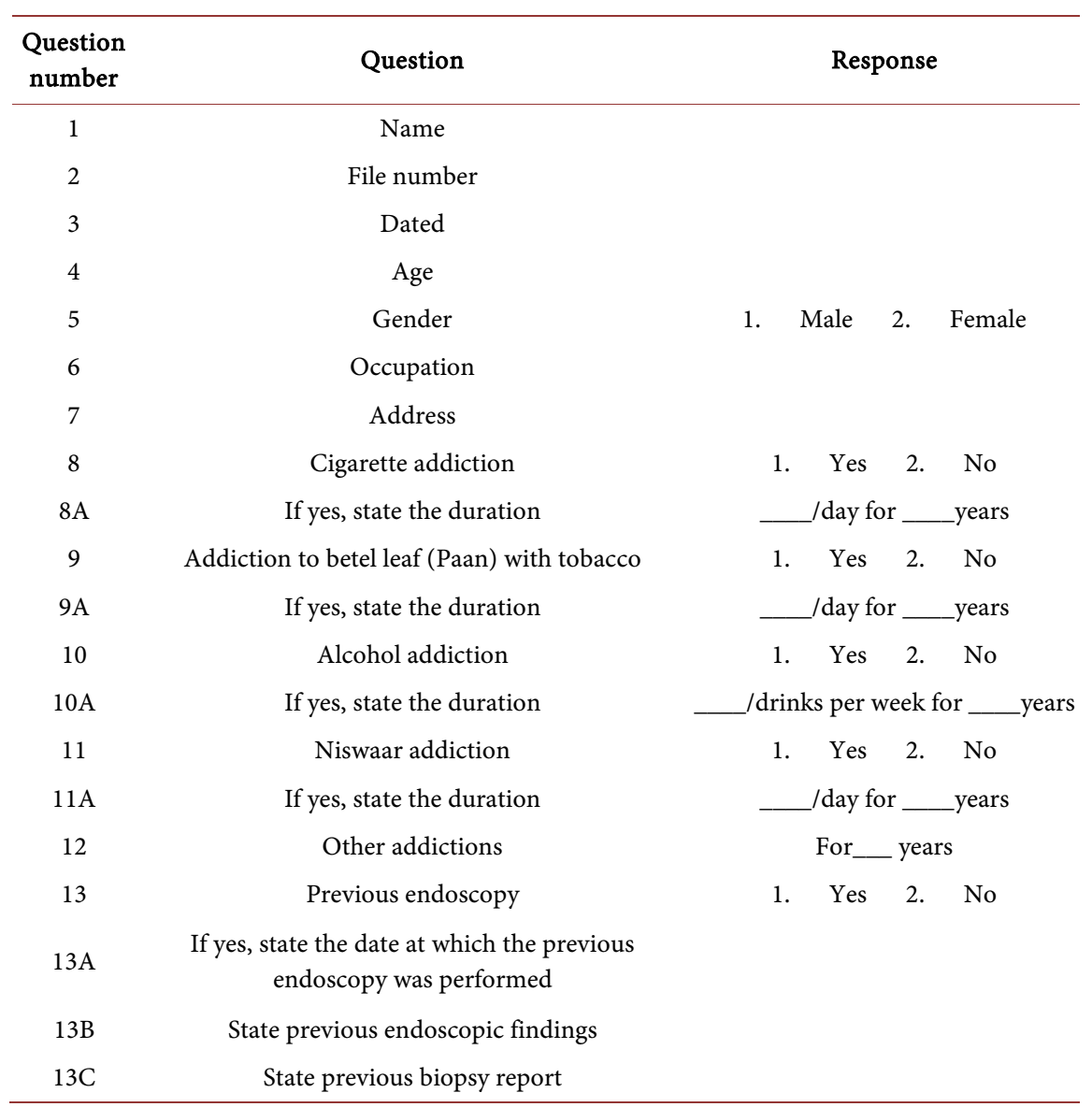

\section{Section II: Symptoms}

\begin{tabular}{lcllll}
\hline 14 & Abdominal pain & 1. & Yes & 2. & No \\
15 & Nausea/vomiting & 1. & Yes & 2. & No \\
16 & Abdominal fullness & 1. & Yes & 2. & No \\
17 & Heartburn & 1. & Yes & 2. & No \\
18 & Flatulence & 1. & Yes & 2. & No \\
19 & Hematemesis & 1. & Yes & 2. & No \\
20 & Melena & 1. & Yes & 2. & No \\
21 & Dysphagia & 1. & Yes & 2. & No \\
22 & Normal bowel habits & 1. & Yes & 2. & No \\
23 & Anemia & 1. & Yes & 2. & No
\end{tabular}


Section III: Family History

\begin{tabular}{lcllll}
\hline 24 & Acid peptic disease & 1. & Yes & 2. & No \\
25 & G. I. malignancy & 1. & Yes & 2. & No \\
26 & Chronic liver disease & 1. & Yes & 2. & No \\
27 & Others & & & & \\
\hline
\end{tabular}

\section{Section IV: Examination Findings}

\begin{tabular}{lcllll}
\hline 28 & Anemia & 1. & Yes & 2. & No \\
29 & Hepatomegaly & 1. & Yes & 2. & No \\
30 & Abdominal tenderness & 1. & Yes & 2. & No \\
31 & Jaundice & 1. & Yes & 2. & No \\
32 & Splenomegaly & 1. & Yes & 2. & No \\
33 & Abdominal mass & 1. & Yes & 2. & No \\
34 & Ascites & 1. & Yes & 2. & No \\
35 & Shrunken liver & 1. & Yes & 2. & No \\
36 & Others & & & & \\
\hline
\end{tabular}

\section{Section V: Investigations}

\begin{tabular}{|c|c|c|c|c|c|}
\hline 37 & Blood $\mathrm{Hb}$ & & \multicolumn{3}{|c|}{$\ldots \mathrm{mg} / \mathrm{dl}$} \\
\hline 38 & Platelet count & & \multicolumn{3}{|c|}{$\ldots 10^{9}$} \\
\hline 39 & Prothrombin time of patient & & \multicolumn{3}{|c|}{ _seconds } \\
\hline 40 & Control Prothrombin time & & \multicolumn{3}{|c|}{ _seconds } \\
\hline 41 & APTT of patient & & \multicolumn{3}{|c|}{ _seconds } \\
\hline 42 & Control APTT & & \multicolumn{3}{|c|}{ _ seconds } \\
\hline 43 & HBsAg & 1. & Yes & 2. & No \\
\hline 44 & HBV DNA & 1. & Yes & 2. & No \\
\hline 45 & Anti-HCV & 1. & Yes & 2. & No \\
\hline 46 & HCV RNA & 1. & Yes & 2. & No \\
\hline 47 & Ultrasounds & 1. & Yes & 2. & No \\
\hline 48 & CT/MRI of abdomen/chest & 1. & Yes & 2. & No \\
\hline 49 & Barium studies & 1. & Yes & 2. & No \\
\hline 50 & LFTs & 1. & Yes & 2. & No \\
\hline 51 & Serum proteins & 1. & Yes & 2. & No \\
\hline 52 & Ascitic fluid & 1. & Yes & 2. & No \\
\hline 53 & H. pylori & 1. & Yes & 2. & No \\
\hline 54 & Others & & & & \\
\hline
\end{tabular}




\section{Section VI: Endoscopy Outcome}

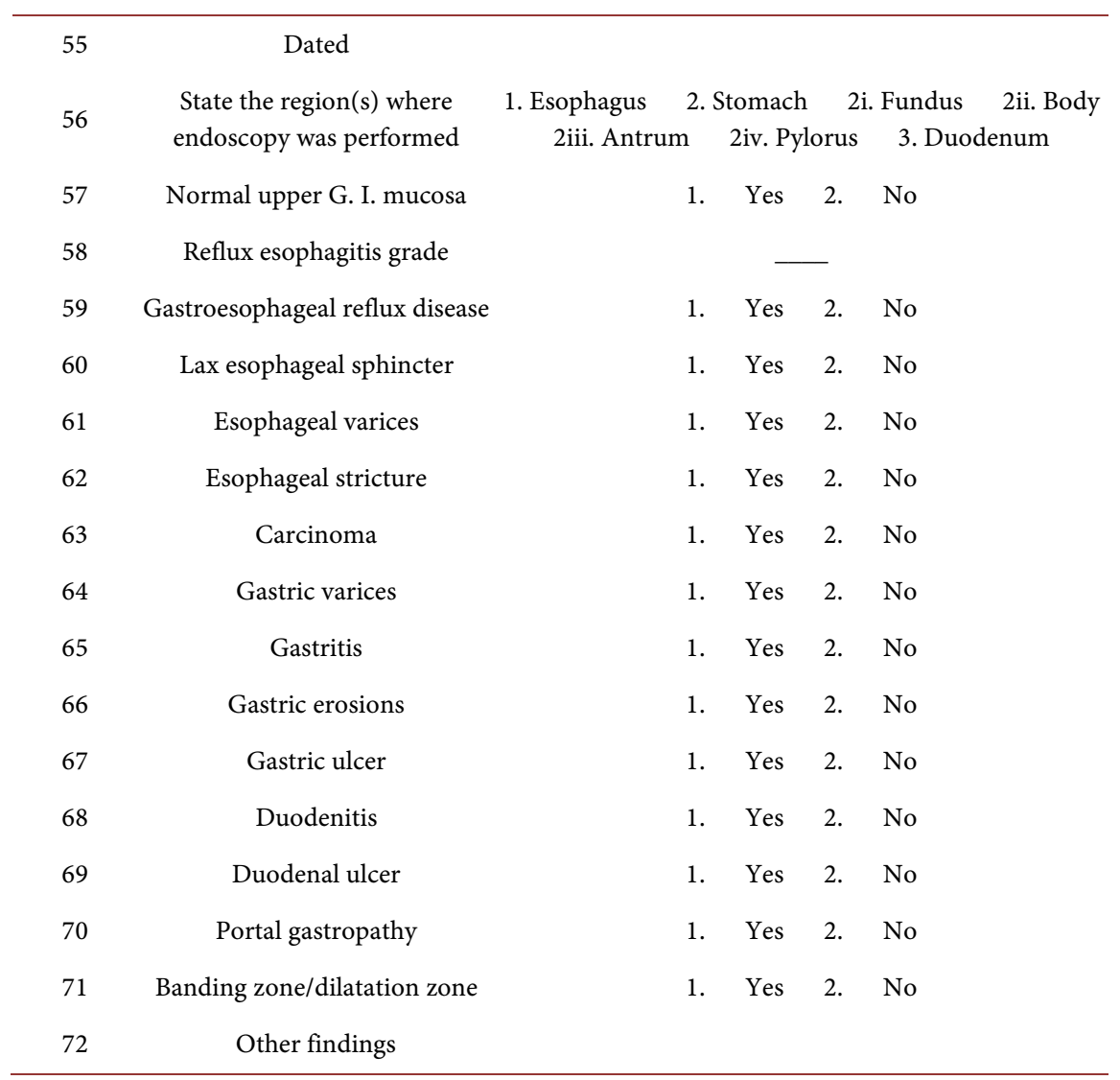

